204

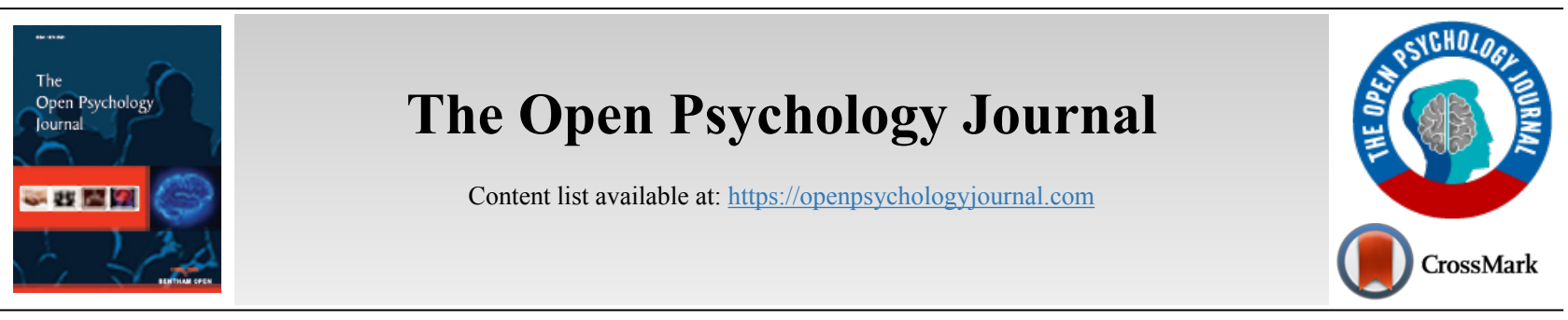

SYSTEMATIC REVIEW

\title{
Using an Embodiment Technique in Psychological Experiments with Virtual Reality: A Scoping Review of the Embodiment Configurations and their Scientific Purpose
}

\author{
Mattia Furlan ${ }^{1}$ and Anna Spagnolli ${ }^{1,2, *}$ \\ ${ }^{1}$ Department of General Psychology, University of Padua, Padova, Italy \\ ${ }^{2}$ Department of General Psychology and Human Inspired Technologies Research Centre, University of Padua, Padova, Italy
}

\begin{abstract}
:
Background:

In recent years, psychological studies with virtual reality have increasingly involved some eEmbodiment tTechnique (ET) in which the users' bodily movements are mapped on the movements of a digital body. However, this domain is very fragmented across disciplines and plagued by terminological ambiguity.

Objective:

This paper provides a scoping review of the psychological studies deploying some ET in VR.

Methods:

A total of 742 papers were retrieved from Scopus and the ACM Digital library using "embodiment" and "virtual reality" as keywords; after screening them, 79 were eventually retained. From each study, the following information was extracted: (a) the content of the virtual scenario, (b) the extent of the embodiment, and (c) the scientific purpose and measure of the psychological experience of embodiment. This information is summarized and discussed, as well as reported in tabular format for each study.

Results:

We first distinguished ET from other types of digital embodiment. Then we summarized the ET solutions in terms of the completeness of the digital body assigned to the user and of whether the digital body's appearance resembled the users' real one. Finally, we report the purpose and the means of measuring the users'sense of embodiment.

\section{Conclusion:}

This review maps the variety of embodiment configurations and the scientific purpose they serve. It offers a background against which other studies planning to use this technique can position their own solution and highlight some underrepresented lines of research that are worth exploring.
\end{abstract}

Keywords: Users' embodiment technique, Virtual reality, Sense of embodiment, Body tracking, Self-location, Measurement.

\begin{tabular}{|l|l|l|l|}
\hline Article History & Received: February 05, 2021 & Revised: June 14, 2021 & Accepted: July 12, 2021 \\
\hline
\end{tabular}

\section{INTRODUCTION}

The first attempts to integrate a user's body into a graphical and interactive digital object date back to the early Nineties [1 4]. In 1994, Slater and Usoh described the situation in which the "proprioceptive signals about the disposition and behavior

\footnotetext{
* Address correspondence to this author at the Department of General Psychology and Human Inspired Technologies Research Centre, University of Padova, via Venezia 8, 35131, Padova, Italy; Tel: +390498276644;

Fax:+390498276605 E-mail: anna.spagnolli@unipd.it
}

of the human body and its parts become overlaid with consistent sensory data about the (. . .) "Virtual Body"” [3]. Studies using some Embodiment Techniques (ET) have then accumulated.

The term embodiment is used loosely with reference to various technical solutions, very different from those referred to by Slater and Usoh in the quotation above. For example, sometimes, the term embodiment refers to the bodily appearance of a virtual agent $[5,6]$, such as the virtual agents 
helping to use some software and endowed with a characterlike digital body, such as the animated paper clip in Microsoft Office [7]. Robots are also often described as having an embodiment, with reference, in this case, to their physical appearance and the way it allows them to interact with their surroundings [8]. Even when the term embodiment refers to a digital body assigned to the user, it might merely consist of a digital representation that gives users a visible appearance $[1$, $2,9]$. The purpose of these representations is to strengthen the social presence of the user interacting with other users in a digital environment or to facilitate remote collaboration by conveying information such as the users' location, state of activity, attention focus, or availability $[9,10]$. These representations are not coupled with the user's real movements.

The kind of embodiment referred to by Slater and Usoh requires interactivity, namely that the digital body moves based on the users' movements. As a result, the user will feel to control the virtual body, own it, and be present in it (sense of embodiment, SE), [12-15]. Interactivity, in which the users can act upon virtual objects [15], and receive timely feedback from those actions [16 - 18], is the factor making a digital world appear as real [19]. In the specific case of a digital body, interactivity makes it feel so real that the participant's body boundaries and configuration will be altered. This experiential alteration is confirmed by neuropsychological evidence; for instance, maneuvering a stick in a virtual environment results in including that stick in the user's peri-personal space, cognitively coded in the same way as the user's natural body [20]. The same phenomenon enables therapeutic applications of ET, e.g., correcting a distorted body image [21].

Given the ambiguity of the way in which the term "embodiment" has been used and the distribution of ET studies across disciplines, our objective is to compose a scoping review of state of the art in VR psychological experiments that use some kind of ET. While a systematic review answers a research question, a scoping review covers the literature in a certain domain to summarize and disseminate its research findings [22]. In this review, Embodiment Techniques (ET) identifies those technical solutions that couple the users' movements with a digital body's movement by using advanced tracking systems. Sense of Embodiment (SE) instead, is "the ensemble of sensations that arise in conjunction with being inside, having, and controlling a body especially in relation to virtual reality applications" [11]. The existing reviews on ET focus on the sense of presence [23], self-reported measures of embodiment in an avatar [24, 25], or the definition of embodiment [11]. The findings we want to summarize here are the technical configuration of the ET in VR and the scientific purpose they served. Having this information will allow new studies to position more clearly their methodology within the current options and make their results easier to compare with the existing ones.

\section{METHODS}

To collect the set of papers for this review, we used Scopus and the ACM Digital library as databases. The former is Elsevier's comprehensive database of peer-reviewed scientific papers that also includes conference proceedings; the latter covers all peer-reviewed works published in the journals and conferences sponsored by ACM and IEEE, the two largest international scientific associations for scholars of computers and interaction with computers. We performed our queries using "embodiment" and "virtual reality" as keywords in February 2019. The search returned 811 records; 8 more records were added because experts recommended them. After removing the duplicates, 750 papers remained. We then screened all the records to select the studies that focused on the users' experience of embodiment. We, therefore, excluded studies that by "embodiment" referred to the mere virtual representation of a person or character; or referred to the appearance of an artificial agent; or did not include tracking some users' body parts; or described some technological solutions without analyzing the users' experience of embodiment. On their titles and abstracts, we performed the first screening for relevance, further reducing the sample to 208 papers; a second screening was performed on the full text of these papers, leading to a sample of 79 publications, all in English (Fig. 1).

We then extracted information from each publication according to a template that fitted the purpose of our study. We extracted descriptive information about the research settings and methods to reflect the state of the art of the ET domain, consistently with the purpose of a scoping review [22]. Since we did not re-code the findings or extract information according to coding schemes that required a subjective judgment, we did not resort to independent coders. The information extracted was the sample composition, the content of the virtual environment, the devices adopted to track the users' body, the level of embodiment, the purpose with which ET was used, and the measures of the psychological experience of being embodied in a digital object. This punctual information is reported as Annex 1. In the rest of this paper, we will summarize the information extracted; we will describe the content of the virtual scenarios (section 3.1.2), the extent of the digital embodiment (section 3.1.1), the scientific purpose of ET (sections 3.2.1) and measure of the psychological experience of embodiment (section 3.2.2). We will conclude by pointing out which lines of investigation are underdeveloped.

\section{RESULTS}

\subsection{Technical Solutions}

\subsubsection{Embodiment Level}

The studies reviewed here vary in the completeness of the digital body assigned to the user, as summarized in Fig. (2). The digital environment can assign a complete body to the user (full body) or just some bodily parts. Of the 79 studies analyzed here, 57 provided the user with an entire virtual body $(72.2 \%)$. In the other cases, only the body parts of relevance to the goal of the study were represented, e.g., hands and arms [25], hands and feet [26], hands and torso [27], or some substituted/modified parts of the body [28, 29]. The choice depends on the object of the study, which makes it relevant that only some parts of the digital body interact with the surrounding environment or are visible. For instance, $\mathrm{Ku}$ et al. [25] investigated the brain activation during a simple action in the virtual environment offering the participant a first-person perception of their virtual body. The action, in this case, was a handshake and, therefore, the embodiment only consisted of a visible digital forearm and hand. In the case of Kondo and colleagues [26], the very purpose of the study was to limit the completeness of the digital embodiment to test if it was effective; they investigated whether showing only the digital hands and feet in the VE could be sufficient to make participants believe that they owned the virtual body. 

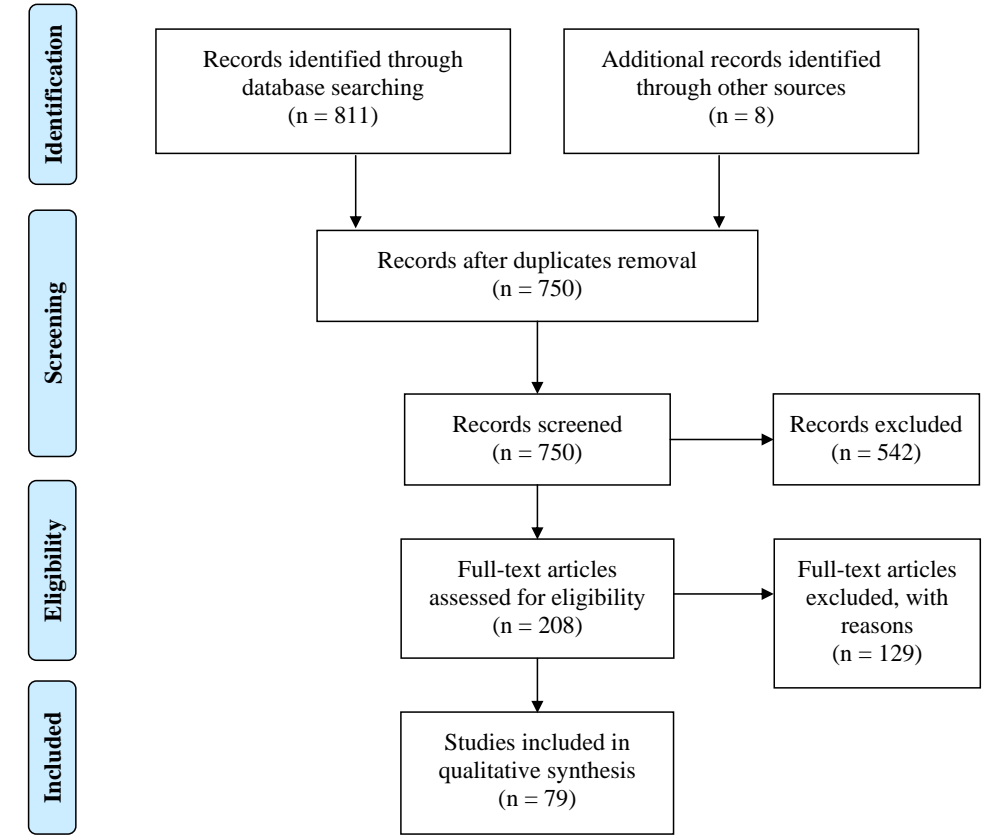

Fig. (1). A flowchart representing the papers' selection procedure.
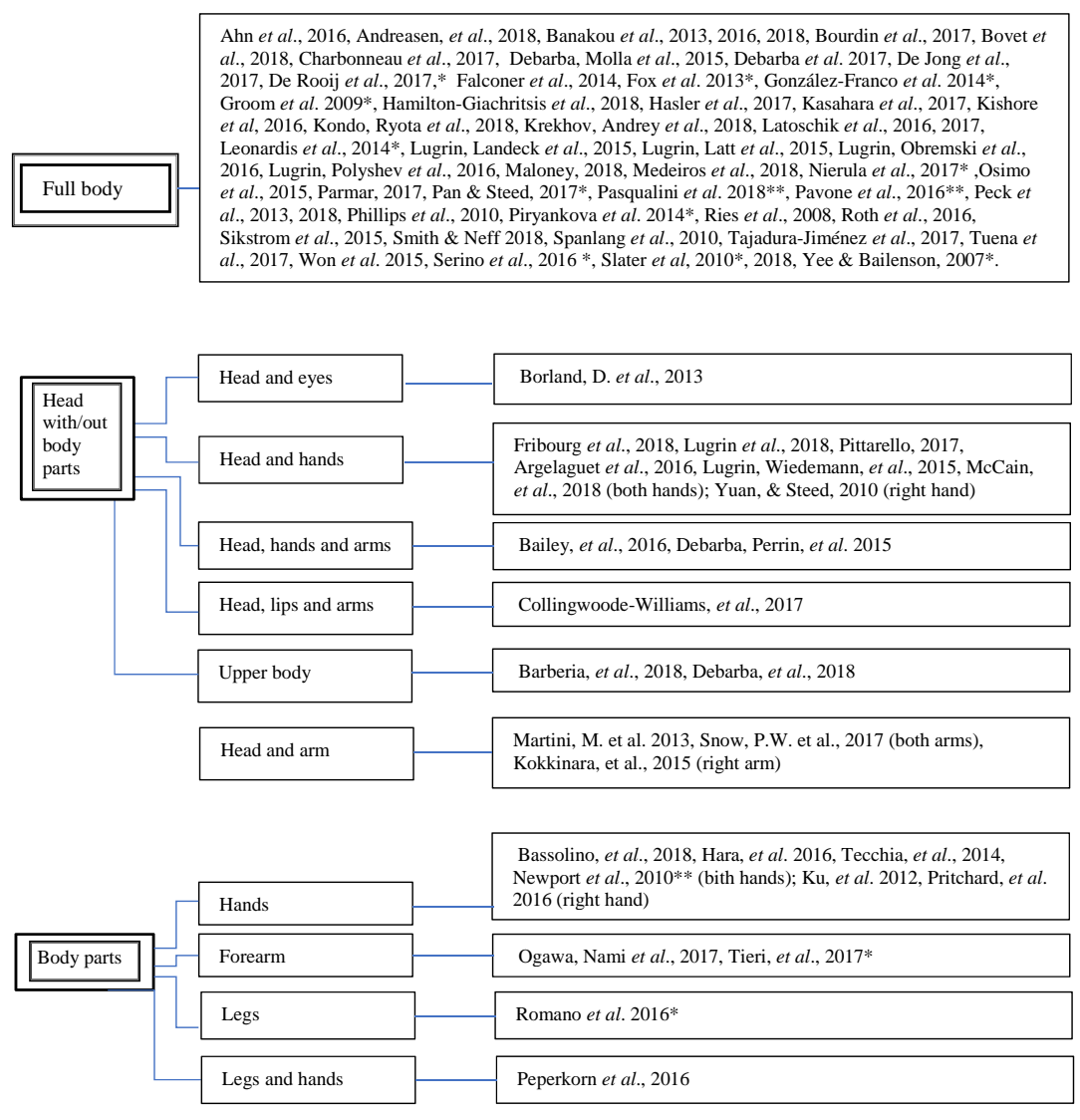

Fig. (2). The completenss of the user's digital body in the studies reviewed here (*Head tracking only, **No tracking).

The mapping of the users' bodily movements into the movements of the digital body was obtained in most cases via tracking devices. However, not all studies tracked the users' entire body, even when the digital body was displayed in the virtual environment was a complete body. Indeed, there was no correspondence between the extent of the digital body and the extent to which the study equipment tracked the user's real body. When there was no need to differentiate the movements 
of the different parts of the body, the digital body could be obtained by simply tracking the user's orientation (studies marked by one asterisk in Fig. (2)) via a Head-Mounted Display (HMD) (92.4\%). De Jong and colleagues [30], for example, investigated whether touch affected the body ownership illusion (BOI); thus, they organized the digital and real environment so that the participant could simultaneously receive a virtual and digital stroking gesture, to check whether the sense of ownership of the virtual body was affected. This experimental paradigm did not require tracking the participants' body movements inside the VE.

Instead, when there was a need to separately control the movements of different parts of the digital body, then additional tracking devices were used. For example, Argelaguet et al. [31] studied how the visual realism of the hand representation affected the sense of embodiment in VR. They reproduced the participants' hands with three different levels of visual realism (abstract vs. iconic vs. realistic) but kept the same controls, based on a tracking system using Leap motion. Only the most realistic visual representation would accurately map the degrees of freedom of the real and virtual hand. In this study, it was then necessary that the fine movements of the real hand were tracked. The users' hands and arms are tracked via wireless controllers [27, 32 - 34], touchless devices such as Leap Motion [31, 35, 36] or optical, infrared cameras paired with active markers (LED sensors) or passive markers (retro-reflective trackers) [29, 37 - 39]. In one paper, even the lip movement was tracked with a microphonebased tool, Lipsync [40]. In some studies (48.1\%), all major body parts were tracked, making it possible to control the different parts of the digital body with the user's real body movements. Hamilton-Giachritsis et al. [41], for instance, investigated the mothers' perspective-taking and empathy with children. The mothers participating in the study were digitally embodied in a virtual 4-year-old child and interacted with a virtual mother having a relaxed or angry attitude. In this study, the whole body of the mothers was tracked and synchronized with the virtual body. In most cases, the body was tracked by pairing an infrared-cameras system with several markers positioned on the participant via tight-fitting suits $(68.4 \%$; of the 38 studies with a full-body tracking); other motion-sensing devices were the Kinect, a marker-free motion capture system [26, 42 - 47], and, more recently, camera-free motion tracking devices, such as Vive [48, 49], which offered a fullembodiment set-up at a relatively low budget.

\subsubsection{Digital Content}

All studies but four [42, 43, 47, 50] allowed users to experience their virtual body (or body parts) from a first-person perspective. The digital body's appearance either resembled or modified the users' real one, depending on the research goal. The users' gender was swapped to test stereotypical threat [51]; its age was modified to study object size-estimation [52, 53], compassionate responses [54], maternal perspective-taking, and empathy [41]; the skin color was manipulated to study racial prejudice [49, 55 - 58], and pain threshold [29]; the appearance was sexualized to study women's body objectification [59]; and body weight and body dimension were modified to study one's body representation [60], the body- ownership illusion [30,61], object size-estimation [36] and perceived pain [62].

Digital embodiments that did not display any gender, age, or race feature have also been used; mannequin-like avatars appeared in a study on social interactions [63], silver and undetailed avatars were used in a study on spatial cognition [39], and alien-like avatars were used in a study investigating the near-death experience [64]. Participants had been given the virtual appearance of famous people such as Albert Einstein [65], Sigmund Freud [66], Lenin [34], or Kim Kardashian [33], to study the effect on the performance of taking somebody else's perspective. Some studies investigated body-ownership using animal-like avatars such as bats [48, 67], tigers and spiders [48], cows and corals [68], fictional creatures like Godzilla [69], and angels [70].

The virtual environment also can either reproduce the user's real environment or be different from it. In the former case, the embodied user would sit at a table in a room similar to the real lab [36, 51, 61, 71 - 77]. In the latter case, the research goal and the experimental task would require users to inhabit a virtual environment that is very different from the physical one: outdoor environments, such as terrains with trees [70], virtual oceans [68], or alien islands [64]; indoor environments such as flats [78], hallways [79], rooms with furniture [80, 81], or libraries [26]; urban landscapes $[12,45,69]$, and environments from past time in history $[34,35]$.

\subsection{Psychological Effects of the Embodiment Technique}

\subsubsection{Purpose of Applying the ET Technique}

We included in this review only the studies that, in addition to using an ET, were interested in the psychological effects of being embodied in a digital object. The specific purpose of ET in each study in this review is listed in the Annex. We will summarize these purposes here by distinguishing between studies in which the sense of embodiment was the primary concern and those in which it was instrumental to studying other psychological phenomena.

Among the studies focused on the psychological experience of embodiment, some aimed at finding an effective technical apparatus able to generate a sense of embodiment. They would study the effectiveness of a specific technical setup $[32,72,90]$ or compare the effectiveness of different technical setups $[71,91,92]$. Some technical options differed in terms of their psychological properties, i.e., the sensory/perceptual/motor feedback [12, 26, 50, 75, 90, 91], the field of view [37], the perspective on the virtual body [13, 46], the level of pictorial realism [31, 92], or the agency [67]. Some studies tested the effectiveness of embodiments that were highly different from the real users' body in terms of functioning or appearance [48, 62, 93 - 100]. Finally, among the studies focused on the psychological experience of embodiment, some were interested in exploring its neurological correlates [26, 73, 101].

Of the studies using embodiment techniques to affect some other psychological processes, some were using ET to boost the effectiveness of the digital experience, such as enjoyment $[34,35]$ or performance (task performance, e.g., completion 
time [96, 97], limb movement during rehabilitation [69], fitness performance [92], cognitive tasks [65], game performance [27], and embodied cognition [98]). This improvement would be engendered by simply endowing the user with a digital embodiment, or, in other cases, by endowing them with a digital body whose attributes differed from the users' real ones, i.e., a fitter body [42].

Psychological effects were also investigated by modifying specific aspects of the embodiment. The digital embodiments changed the users' social identity and, in turn, their perception of discriminated social categories [49, 56 - 59], children [41], nature [69], the architectonic environment [99], or of themselves (self-compassion [54],). The new identity could affect the performance in a specific task, such as finding new solutions [66], having creative ideas [80], overcoming fear responses [100] or stereotypes threats [51]; and it could change the users' preferences (e.g., narcissistic choices [33], selfconfidence and self-disclosure [101], self-objectification [59]). Specific manipulations of the digital embodiment affected body perception (rubber hand illusion [102]), the estimation of body width and circumference [60] or weight [103] and even some bodily states (hand temperature [77]). It affected spatial perception, such as the estimation of the size of objects [36, 38, 52], distance perception [79], space-valance association [39], or accuracy in judging egocentric distances [104]. And it affected the response to stimuli, such as pain [62, 76, 81, 105], threat [28] or phobic stimuli [74].

\subsubsection{Measures of the Sense of Embodiment}

While the ET consists of using a specific technical setup, the sense of embodiment (SE) refers to the psychological effect resulting from using this technique to interact with the virtual environment. The SE combines three feelings: self-location, a sense of agency over the virtual body, and body ownership [11 - 14].

- By self-location, the literature refers to the "spatial experience of being inside a body" and is different from the sense of being located within the virtual environment as a whole (spatial presence [11, 14]. Self-location is captured by using behavioral indices such as affordance estimation and body size estimation [61], proprioceptive judgments of space and body [38] and self-report questionnaires $[11,13,91]$.

- The sense of agency is the sense of having motor and action control of the body driven by intention and will $[31,37,51,53,56,67,90,106]$. Agency is believed to require congruence between the expected movement and the movement perceived by the senses (visuomotor correlation) [11, 14]. Firstly explored by Peck and colleagues with a six-item scale [57], questionnaires measuring agency have also included measures of the perception of the self-reflection generated by a virtual mirror and of the body as it is seen by looking down at oneself $[40,41,52,55,64$ 66]. Subdimensions of the agency include movement, enjoyment of body control, movement control, and movement cause [43]. Agency, in turn, can be a subcomponent of the illusion of virtual body ownership [47].

- The sense of body ownership is the self-attribution of a body (virtual or physical), deriving from sensory information (e.g., visual, tactile, or proprioceptive). It is believed to derive from synchronizing the real with the virtual body $[11,107]$ and was initially studied in association with the rubber hand illusion with a questionnaire [108]. That questionnaire was then adapted to fit settings with a full virtual body $[32,75$, 77]. Ad hoc scales [86] or mixed-method questionnaires with open and closed-ended questions $[42,109]$ have also been used. Besides questionnaires, body ownership has also been measured with physiological indices [12, 28, 74, 78, 109] electroencephalogram, and electromyography [72].

\section{DISCUSSION}

In this paper, we collected and offered an overview of the existing solutions to display, capture and measure the users' embodiment in virtual reality to improve the recognizability and focus of a concept that has often been used loosely. To conclude, we will describe the areas in which future efforts can be devoted.

First, less than half studies $(48.1 \%)$ provided users with full-body tracking. Many of the studies only used an HMD to adapt the digital body to the position of the user's body. Since full-body tracking is becoming more common and affordable, it should be increasingly considered in studies investigating social interactions or spatial perception.

Second, only a few studies ventured to consider the interaction between embodied users; this remains an unexplored terrain open to future investigation [32, 63, 110]. This could be improved in combination with the usage of virtual environments where two embodied users are co-present and interact. The virtual environments adopted in ET studies are mostly designed to be visited by one user at a time; the studies foreseeing multiple users connected at a distance $[1,2$, $111]$ or located in the same physical environment $[32,59,63$, $101,110]$ are infrequent.

Third, we included in this review only the studies that, in addition to using an ET, were interested in investigating the psychological effects of being embodied in a digital object. But many other studies explore some technical solutions that are assumed to induce SE but are not tested with users. We encourage the use of measurements listed in this review to validate the designers' claims.

\section{CONCLUSION}

Finally, it might be worth emphasizing that although embodiment helps to achieve a sense of presence $[3,25,79]$ or empathy [112], it is not a necessary condition to them. Sense of presence and empathy can be achieved by interacting with the VE via non-embodied input modalities without having the body graphically represented in the VR $[113,114]$. Therefore, including an ET in the technical setup of ones' study should be motivated by exploiting within the narrative the interactive possibilities of the virtual body. 


\section{LIST OF ABBREVIATIONS}

$\begin{array}{lll}\text { VR } & = & \text { Virtual Reality } \\ \text { VE } & = & \text { Virtual Environment } \\ \text { HMD } & = & \text { Head-Mounted Display } \\ \text { ET } & = & \text { Embodiment Technique } \\ \text { SE } & = & \text { Sense of Embodiment }\end{array}$

\section{CONSENT FOR PUBLICATION}

Not applicable.

\section{STANDARDS OF REPORTING}

PRISMA guidelines were followed in this study.

\section{FUNDING}

This study was supported by a grant from Ministero dell'istruzione, dell'università e della ricerca (Dipartimenti di Eccellenza DM 11/05/2017 n. 262) to the Department of General Psychology of the University of Padova, and by the University of Padova via a doctoral fellowship.

\section{CONFLICT OF INTEREST}

The authors declare no conflict of interest, financial or otherwise.

\section{ACKNOWLEDGEMENTS}

Declared none.

\section{REFERENCES}

[1] Bowers J, Pycock J, O'Brien J. Talk and embodiment in collaborative virtual environments. Conf. Hum. Factors Comput. Syst. - Proc 1996; pp. 58-65.

[http://dx.doi.org/10.1145/238386.238404]

[2] Balcisoy S, Thalmann D. Hybrid participant embodiments in networked collaborative virtual environments. Proc. - 1998 Multimed. Model MMM 1998; 1998: 130-7.

[http://dx.doi.org/10.1109/MULMM.1998.722988]

[3] Slater M, Usoh M. Body centred interaction in immersive virtual environments. Artif Life Virtual Real 1994; 1: 125-48.

[4] Biocca F. The Cyborg's dilemma: Progressive embodiment in virtual environments. J Comput Commun 1997; p. 3.

[5] Cassell J, Sullivan J, Churchill E, Prevost S. Embodied conversational agents. MIT press 2000.

[http://dx.doi.org/10.7551/mitpress/2697.001.0001]

[6] Li J, Kizilcec R, Bailenson J, Ju W. Social robots and virtual agents as lecturers for video instruction. Comput Human Behav 2016; 55: 1222-30.

[http://dx.doi.org/10.1016/j.chb.2015.04.005]

[7] Serenko A, Bontis N, Detlor B. End-user adoption of animated interface agentsin everyday work applications. Behav Inf Technol 2007; 26: 119-32.

[http://dx.doi.org/10.1080/01449290500260538]

[8] Wa J, Feil-seifer DJ, Shell DA, Mataric MJ. Embodiment and HumanRobot Interaction : A Task-Based Perspective. 2007; pp. 872-7.

[9] Benford S, Bowers J, Fahlén LE, Greenhalgh C, Snowdon D. Embodiments, avatars, clones and agents for multi-user, multi-sensory virtual worlds. Multimedia Syst 1997; 5: 93-103.

[http://dx.doi.org/10.1007/s005300050045]

[10] Mennecke BE, Triplett JL, Hassall LM, Conde ZJ. Embodied social presence theory. Proc Annu Hawaii Int Conf Syst Sci. [http://dx.doi.org/10.1109/HICSS.2010.179]

[11] Kilteni K, Groten R, Slater M. The Sense of Embodiment in Virtual Reality. Presence Teleoperators Virtual Environ 2012; 21: 373-87. [http://dx.doi.org/10.1162/PRES_a_00124]

[12] Leonardis D, Frisoli A, Barsotti M, Carrozzino M, Bergamasco M. Multisensory feedback can enhance embodiment within an enriched virtual walking scenario. Presence Teleoperators Virtual Environ 2014; 23: 253-66.

[http://dx.doi.org/10.1162/PRES_a_00190]

[13] Debarba HG, Molla E, Herbelin B, Boulic R. Characterizing embodied interaction in First and Third Person Perspective viewpoints. 2015 IEEE Symp 3D User Interfaces, 3DUI 2015 - Proc 2015; 67-72. [http://dx.doi.org/10.1109/3DUI.2015.7131728]

[14] Longo MR, Schüür F, Kammers MPM, Tsakiris M, Haggard P. What is embodiment? A psychometric approach. Cognition 2008; 107(3): 978-98.

[http://dx.doi.org/10.1016/j.cognition.2007.12.004] [PMID: 18262508]

[15] Slater M, Steed A, McCarthy J, Maringelli F. The influence of body movement on subjective presence in virtual environments. Hum Factors 1998; 40(3): 469-77.

[http://dx.doi.org/10.1518/001872098779591368] [PMID: 9849105]

[16] Zahorik P, Jenison RL. Presence as being-in-the-world. Presence Teleoperators Virtual Environ 1998; 7: 78-89.

[http://dx.doi.org/10.1162/105474698565541]

[17] Gamberini L, Spagnolli A. An action-based approach to presence: Foundations and methods Immersed Media Telepresence Theory, Meas Technol. Springer 2015; pp. 101-14.

[http://dx.doi.org/10.1007/978-3-319-10190-3 6]

[18] Slater M. Place illusion and plausibility can lead to realistic behaviour in immersive virtual environments. Philos Trans R Soc Lond B Biol Sci 2009; 364(1535): 3549-57.

[http://dx.doi.org/10.1098/rstb.2009.0138] [PMID: 19884149]

[19] Lee KM. Presence, Explicated. Commun Theory 2004; 14: 27-50. [http://dx.doi.org/10.1111/j.1468-2885.2004.tb00302.x]

[20] Gamberini L, Seraglia B, Priftis K. Processing of peripersonal and extrapersonal space using tools: evidence from visual line bisection in real and virtual environments. Neuropsychologia 2008; 46(5): 1298-304.

[http://dx.doi.org/10.1016/j.neuropsychologia.2007.12.016] [PMID: 18242649]

[21] Ferrer-García M, Gutiérrez-Maldonado J. The use of virtual reality in the study, assessment, and treatment of body image in eating disorders and nonclinical samples: a review of the literature. Body Image 2012; 9(1): $1-11$.

[http://dx.doi.org/10.1016/j.bodyim.2011.10.001] [PMID: 22119329]

[22] Arksey H, O'Malley L. Scoping studies: Towards a methodological framework. Int J Soc Res Methodol Theory Pract 2005; 8: 19-32. [http://dx.doi.org/10.1080/1364557032000119616]

[23] Schultze U. Embodiment and presence in virtual worlds: A review. J Inf Technol 2010; 25: 434-49. [http://dx.doi.org/10.1057/jit.2009.25]

[24] Gonzalez-Franco M, Peck TC. Avatar embodiment. Towards a standardized questionnaire. Front Robot AI 2018; 5: 74 [http://dx.doi.org/10.3389/frobt.2018.00074] [PMID: 33500953]

[25] Ku J, Lee H, Kim J-J, Kim IY, Kim SI. Brain mechanism involved in the real motion interaction with a virtual avatar. Biomed Eng Lett 2012; 2 : 164-72.

[http://dx.doi.org/10.1007/s13534-012-0068-5]

[26] Kondo R, Sugimoto M, Minamizawa K, Hoshi T, Inami M, Kitazaki M. Illusory body ownership of an invisible body interpolated between virtual hands and feet via visual-motor synchronicity. Sci Rep 2018; 8(1): 7541 .

[http://dx.doi.org/10.1038/s41598-018-25951-2] [PMID: 29765152]

[27] Lugrin J-L, Ertl M, Krop P, Klupfel R, Stierstorfer S, Weisz B, et al. Any "Body" There? Avatar visibility effects in a virtual reality game. 25th IEEE Conf Virtual Real 3D User Interfaces, VR. 17-24.

[http://dx.doi.org/10.1109/VR.2018.8446229]

[28] Yuan Y, Steed A. Is the rubber hand illusion induced by immersive virtual reality? Virtual Real Conf (VR). IEEE 2010; pp. 95-102.

[29] Martini M, Perez-Marcos D, Sanchez-Vives MV. What color is my arm? Changes in skin color of an embodied virtual arm modulates pain threshold. Front Hum Neurosci 2013; 7: 438.

[http://dx.doi.org/10.3389/fnhum.2013.00438] [PMID: 23914172]

[30] de Jong JR, Keizer A, Engel MM, Dijkerman HC. Does affective touch influence the virtual reality full body illusion? Exp Brain Res 2017; 235(6): 1781-91.

[http://dx.doi.org/10.1007/s00221-017-4912-9] [PMID: 28289799]

[31] Argelaguet F, Hoyet L, Trico M, Lécuyer A. The role of interaction in virtual embodiment: Effects of the virtual hand representation.Proc IEEE Virtual Real. 2016; pp. 3-10.

[http://dx.doi.org/10.1109/VR.2016.7504682]

[32] Fribourg R, Argelaguet F, Hoyet L, Lecuyer A. Studying the sense of embodiment in VR shared experiences. 25th IEEE Conf Virtual Real 
3D User Interfaces, VR 2018 - Proc. 273-80. [http://dx.doi.org/10.1109/VR.2018.8448293]

[33] McCain J, Ahn SJG, Campbell WK. Is Desirability of the Trait a Boundary Condition of the Proteus Effect? A Pilot Study. Commun Res Rep 2018; 35: 445-55.

[http://dx.doi.org/10.1080/08824096.2018.1531212]

[34] Slater M, Navarro X, Valenzuela J, et al. Virtually being Lenin enhances presence and engagement in a scene from the Russian Revolution. Front Robot AI 2018; 5: 91

[http://dx.doi.org/10.3389/frobt.2018.00091] [PMID: 33500970]

[35] Pittarello F. Experimenting with PlayVR, a virtual reality experience for the world of theater. ACM Int Conf Proceeding Ser. Part F1313 [http://dx.doi.org/10.1145/3125571.3125596]

[36] Ogawa N, Narumi T, Hirose M. Distortion in Perceived Size and Body-based Scaling in Virtual Environments.Proc 8th Augment Hum Int Conf. New York, NY, USA: ACM 2017; p. 35.

[http://dx.doi.org/10.1145/3041164.3041204]

[37] Debarba HG, Perrin S, Herbelin B, Boulic R. Embodied interaction using non-planar projections in immersive virtual reality. Proc ACM Symp Virtual Real Softw Technol VRST. 13-15: 128-8.

[http://dx.doi.org/10.1145/2821592.2821603]

[38] Kokkinara E, Slater M, López-Moliner J. The effects of visuomotor calibration to the perceived space and body, through embodiment in immersive virtual reality. ACM Trans Appl Percept 2015; 13 [http://dx.doi.org/10.1145/2818998]

[39] Bailey JO, Bailenson JN, Casasanto D. When does virtual embodiment change our minds? Presence Teleoperators Virtual Environ 2016; 25: 222-33.

[http://dx.doi.org/10.1162/PRES_a_00263]

[40] Collingwoode-Williams T, Gillies M, McCall C, Pan X. The effect of lip and arm synchronization on embodiment: A pilot study. Proc. IEEE Virtual Real 2017; pp. 253-4.

[http://dx.doi.org/10.1109/VR.2017.7892272]

[41] Hamilton-Giachritsis C, Banakou D, Garcia Quiroga M, Giachritsis C, Slater M. Reducing risk and improving maternal perspective-taking and empathy using virtual embodiment. Sci Rep 2018; 8(1): 2975. [http://dx.doi.org/10.1038/s41598-018-21036-2] [PMID: 29445183]

[42] Lugrin J-L, Landeck M, Latoschik ME. Avatar embodiment realism and virtual fitness training. In: 2015 IEEE Virtual Real Conf VR 2015 - Proc. 2015; pp. 225-6.

[http://dx.doi.org/10.1109/VR.2015.7223377]

[43] Latoschik ME, Lugrin J-L, Roth D. FakeMi: A fake mirror system for avatar embodiment studies. Proc ACM Symp Virtual Real Softw Technol VRST. 02-04: 73-6.

[http://dx.doi.org/10.1145/2993369.2993399]

[44] Daily SB, Leonard AE, Jörg S, Babu S, Gundersen K, Parmar D. Embodying Computational Thinking: Initial Design of an Emerging Technological Learning Tool. Technol Knowl Learn 2015; 20: 79-84. [http://dx.doi.org/10.1007/s10758-014-9237-1]

[45] Tuena C, Serino S, Gaston-Bellegarde A, et al. How virtual embodiment affects episodic memory functioning: A proof-of-concept study. Annu Rev Cybertherapy Telemed 2017; 15: 98-103.

[46] Medeiros D, dos Anjos RK, Mendes D, Pereira JM, Raposo A, Jorge J. Keep My Head on My Shoulders!: Why Third-person is Bad for Navigation in VR. Proc. 24th ACM Symp Virtual Real Softw Technol. 16:1-16:10

[http://dx.doi.org/10.1145/3281505.3281511]

[47] Roth D, Lugrin J-LJ-L, Latoschik MEME, Huber S. Alpha IVBO Construction of a Scale to Measure the Illusion of Virtual Body Ownership. Proc. 2017 CHI Conf. Ext. Abstr. Hum. Factors Comput Syst. Part F1276: 2875-83.

[http://dx.doi.org/10.1145/3027063.3053272]

[48] Krekhov A, Cmentowski S, Krüger JVR. Animals: Surreal Body Ownership in Virtual Reality Games. Proc 2018 Annu Symp Comput Interact Play Companion Ext Abstr. 503-11. [http://dx.doi.org/10.1145/3270316.3271531]

[49] Maloney D. Mitigating Negative Effects of Immersive Virtual Avatars on Racial Bias. Proc 2018 Annu Symp Comput Interact Play Companion Ext Abstr - CHI Play '18 Ext Abstr. 39-43. [http://dx.doi.org/10.1145/3270316.3270599]

[50] Lugrin J-L, Obremski D, Roth D, Latoschik ME. Audio feedback and illusion of virtual body ownership in mixed reality. Proc ACM Symp Virtual Real Softw Technol VRST. 02-04: 309-10. [http://dx.doi.org/10.1145/2993369.2996319]

[51] Peck TC, Doan M, Bourne KA, Good JJ. The effect of gender bodyswap illusions on working memory and stereotype threat. IEEE Trans Vis Comput Graph 2018; 24(4): 1604-12.
[http://dx.doi.org/10.1109/TVCG.2018.2793598] [PMID: 29543177]

52] Banakou D, Groten R, Slater M. Illusory ownership of a virtual child body causes overestimation of object sizes and implicit attitude changes. Proc Natl Acad Sci USA 2013; 110(31): 12846-51. [http://dx.doi.org/10.1073/pnas.1306779110] [PMID: 23858436]

[53] Tajadura-Jiménez A, Banakou D, Bianchi-Berthouze N, Slater M. Embodiment in a child-like talking virtual body influences object size perception, self-identification, and subsequent real speaking. Sci Rep 2017; 7(1): 9637.

[http://dx.doi.org/10.1038/s41598-017-09497-3] [PMID: 28851953]

[54] Falconer CJ, Slater M, Rovira A, et al. Embodying compassion: a virtual reality paradigm for overcoming excessive self-criticism. PLoS One 2014; 9(11): e111933.

[http://dx.doi.org/10.1371/journal.pone.0111933] [PMID: 25389766]

[55] Banakou D, Hanumanthu PD, Slater M. Virtual embodiment of white people in a black virtual body leads to a sustained reduction in their implicit racial bias. Front Hum Neurosci 2016; 10: 601.

[http://dx.doi.org/10.3389/fnhum.2016.00601] [PMID: 27965555]

[56] Hasler BS, Spanlang B, Slater M. Virtual race transformation reverses racial in-group bias. PLoS One 2017; 12(4): e0174965.

[http://dx.doi.org/10.1371/journal.pone.0174965] [PMID: 28437469]

[57] Peck TC, Seinfeld S, Aglioti SM, Slater M. Putting yourself in the skin of a black avatar reduces implicit racial bias. Conscious Cogn 2013; 22(3): 779-87.

[http://dx.doi.org/10.1016/j.concog.2013.04.016] [PMID: 23727712]

[58] Groom V, Bailenson JN, Nass C. The influence of racial embodiment on racial bias in immersive virtual environments. Soc Influ 2009; 4: 231-48.

[http://dx.doi.org/10.1080/15534510802643750]

[59] Fox J, Bailenson JN, Tricase L. The embodiment of sexualized virtual selves: The Proteus effect and experiences of self-objectification via avatars. Comput Human Behav 2013; 29: 930-8

[http://dx.doi.org/10.1016/j.chb.2012.12.027]

[60] Serino S, Pedroli E, Keizer A, et al. Virtual reality body swapping: A tool for modifying the allocentric memory of the body. Cyberpsychol Behav Soc Netw 2016; 19(2): 127-33.

[http://dx.doi.org/10.1089/cyber.2015.0229] [PMID: 26506136]

[61] Piryankova IV, Wong HY, Linkenauger SA, et al. Owning an overweight or underweight body: distinguishing the physical, experienced and virtual body. PLoS One 2014; 9(8): e103428. [http://dx.doi.org/10.1371/journal.pone.0103428] [PMID: 25083784]

[62] Romano D, Llobera J, Blanke O. Size and viewpoint of an embodied virtual body affect the processing of painful stimuli. J Pain 2016; 17(3): 350-8

[http://dx.doi.org/10.1016/j.jpain.2015.11.005] [PMID: 26656236]

[63] Roth D, Lugrin J-L, Galakhov D, Hofmann A, et al. Avatar realism and social interaction quality in virtual reality. In: Proc - IEEE Virtual Real. 2016; pp. 277-8.

[http://dx.doi.org/10.1109/VR.2016.7504761]

[64] Barberia I, Oliva R, Bourdin P, Slater M. Virtual mortality and neardeath experience after a prolonged exposure in a shared virtual reality may lead to positive life-attitude changes. PLoS One 2018; 13(11): e0203358.

[http://dx.doi.org/10.1371/journal.pone.0203358] [PMID: 30395568]

[65] Banakou D, Kishore S, Slater M. Virtually being Einstein results in an improvement in cognitive task performance and a decrease in age bias. Front Psychol 2018; 9: 917.

[http://dx.doi.org/10.3389/fpsyg.2018.00917] [PMID: 29942270]

[66] Osimo SA, Pizarro R, Spanlang B, Slater M. Conversations between self and self as Sigmund Freud--A virtual body ownership paradigm for self counselling. Sci Rep 2015; 5: 13899.

[http://dx.doi.org/10.1038/srep13899] [PMID: 26354311]

[67] Andreasen A, Nilsson NC, Serafin S. Agency enhances body ownership illusion of being a virtual bat. 25th IEEE Conf. Virtual Real 3D User Interfaces, VR 2018 - Proc. 505-6. [http://dx.doi.org/10.1109/VR.2018.8446448]

[68] Ahn SJG, Bostick J, Ogle E, Nowak KL, McGillicuddy KT, Bailenson JN. Experiencing Nature: Embodying Animals in Immersive Virtual Environments Increases Inclusion of Nature in Self and Involvement With Nature. J Comput Commun 2016; 21: 399-419.

[http://dx.doi.org/10.1111/jcc4.12173]

[69] Charbonneau P, Dallaire-Cote M, Cote SS-P, et al. Gaitzilla: Exploring the effect of embodying a giant monster on lower limb kinematics and time perception. Int Conf Virtual Rehabil ICVR. 2017 [http://dx.doi.org/10.1109/ICVR.2017.8007535]

[70] Sikstrom E, De Gotzen A, Serafin S. Wings and flying in immersive VR - Controller type, sound effects and experienced ownership and 
agency2015 IEEE Virtual Real Conf VR 2015 - Proc. 2015; pp. 281-. [http://dx.doi.org/10.1109/VR.2015.7223405]

[71] Bassolino M, Franza M, Bello Ruiz J, et al. Non-invasive brain stimulation of motor cortex induces embodiment when integrated with virtual reality feedback. Eur J Neurosci 2018; 47(7): 790-9.

[http://dx.doi.org/10.1111/ejn.13871] [PMID: 29460981]

[72] González-Franco M, Peck TC, Rodríguez-Fornells A, Slater M. A threat to a virtual hand elicits motor cortex activation. Exp Brain Res 2014; 232(3): 875-87.

[http://dx.doi.org/10.1007/s00221-013-3800-1] [PMID: 24337257]

[73] Pavone EF, Tieri G, Rizza G, Tidoni E, Grisoni L, Aglioti SM. Embodying others in immersive virtual reality: Electro-cortical signatures of monitoring the errors in the actions of an avatar seen from a first-person perspective. J Neurosci 2016; 36(2): 268-79.

[http://dx.doi.org/10.1523/JNEUROSCI.0494-15.2016] [PMID: 26758821]

[74] Peperkorn HM, Diemer JE, Alpers GW, Mühlberger A. Representation of patients' hand modulates fear reactions of patients with spider phobia in virtual reality. Front Psychol 2016; 7: 268. [http://dx.doi.org/10.3389/fpsyg.2016.00268] [PMID: 26973566]

[75] Pritchard SC, Zopf R, Polito V, Kaplan DM, Williams MA. Nonhierarchical influence of visual form, touch, and position cues on embodiment, agency, and presence in virtual reality. Front Psychol 2016; $7: 1649$.

[http://dx.doi.org/10.3389/fpsyg.2016.01649] [PMID: 27826275]

[76] Nierula B, Martini M, Matamala-Gomez M, Slater M, Sanchez-Vives MV. Seeing an embodied virtual hand is analgesic contingent on colocation. J Pain 2017; 18(6): 645-55.

[http://dx.doi.org/10.1016/j.jpain.2017.01.003] [PMID: 28108385]

[77] Tieri G, Gioia A, Scandola M, Pavone EF, Aglioti SM. Visual appearance of a virtual upper limb modulates the temperature of the real hand: a thermal imaging study in Immersive Virtual Reality. Eur J Neurosci 2017; 45(9): 1141-51.

[http://dx.doi.org/10.1111/ejn.13545] [PMID: 28222235]

[78] Lugrin J-L, Wiedemann M, Bieberstein D, Latoschik ME. Influence of avatar realism on stressful situation in VR.2015 IEEE Virtual Real Conf VR 2015 - Proc. 2015; pp. 227-8.

[http://dx.doi.org/10.1109/VR.2015.7223378]

[79] Ries B, Interrante V, Kaeding M, Anderson L. The effect of selfembodiment on distance perception in immersive virtual environments. Proc ACM Symp Virtual Real Softw Technol VRST. 167-70.

[http://dx.doi.org/10.1145/1450579.1450614]

[80] De Rooij A, Van Der Land S, Van Erp S. The creative proteus effect: How self-similarity, embodiment, and priming of creative stereotypes with avatars influences creative ideation. C C 2017 - Proc 2017 ACM SIGCHI Conf Creat Cogn. 232-6.

[http://dx.doi.org/10.1145/3059454.3078856]

[81] Snow PW, Sedki I, Sinisi M, Comley R, Loureiro RCV. Robotic therapy for phantom limb pain in upper limb amputees. IEEE Int Conf Rehabil Robot 2017; 2017: 1019-24.

[http://dx.doi.org/10.1109/ICORR.2017.8009383] [PMID: 28813955]

[82] Bourdin P, Barberia I, Oliva R, Slater M. A virtual out-of-body experience reduces fear of death. PLoS One 2017; 12(1): e0169343. [http://dx.doi.org/10.1371/journal.pone.0169343] [PMID: 28068368]

[83] Collingwoode-Williams T, Gillies M, McCall C, Pan X. The effect of lip and arm synchronization on embodiment: A pilot study. Proc. IEEE Virtual Real 2017; pp. 253-4.

[http://dx.doi.org/10.1109/VR.2017.7892272]

[84] Hara M, Ishino Y, Kanayama N, Takasaki M, Yamaguchi D, Mizuno $\mathrm{T}$. A simple action of right index finger induces rubber hand illusion to static left hand. 2016 IEEE Int. Conf. Syst. Man, Cybern SMC 2016 Conf Proc. 737-42.

[http://dx.doi.org/10.1109/SMC.2016.7844329]

[85] Latoschik ME, Roth D, Gall D, Achenbach J, Waltemate T, Botsch M. The effect of avatar realism in immersive social virtual realities. Proc ACM Symp Virtual Real Softw Technol VRST. Part F1319 [http://dx.doi.org/10.1145/3139131.3139156]

[86] Slater M, Spanlang B, Sanchez-Vives MV, Blanke O. First person experience of body transfer in virtual reality. PLoS One 2010; 5(5): e10564.

[http://dx.doi.org/10.1371/journal.pone.0010564] [PMID: 20485681]

[87] Tecchia F, Avveduto G, Carrozzino M, Brondi R, Bergamasco M, Alem L. Interacting with your own hands in a fully immersive MR system. Proc, 2014. 313-4.

[http://dx.doi.org/10.1109/ISMAR.2014.6948466]

[88] Borland D, Peck T, Slater M. An evaluation of self-avatar eye movement for virtual embodiment. IEEE Trans Vis Comput Graph 2013; 19(4): 591-6.

[http://dx.doi.org/10.1109/TVCG.2013.24] [PMID: 23428443]

[89] Spanlang B, Normand J-M, Giannopoulos E, Slater M. A first person avatar system with haptic feedback. Proc ACM Symp Virtual Real Softw Technol VRST. 47-50.

[http://dx.doi.org/10.1145/1889863.1889870]

[90] Bovet S, Debarba HG, Herbelin B, Molla E, Boulic R. The critical role of self-contact for embodiment in virtual reality. IEEE Trans Vis Comput Graph 2018; 24(4): 1428-36.

[http://dx.doi.org/10.1109/TVCG.2018.2794658] [PMID: 29543161]

[91] Galvan Debarba H, Bovet S, Salomon R, Blanke O, Herbelin B, Boulic R. Characterizing first and third person viewpoints and their alternation for embodied interaction in virtual reality. PLoS One 2017; 12(12): e0190109.

[http://dx.doi.org/10.1371/journal.pone.0190109] [PMID: 29281736]

[92] Lugrin J-L, Landeck M, Latoschik ME. Avatar embodiment realism and virtual fitness training. 2015 IEEE Virtual Real. In: Conf VR 2015 - Proc. 2015; pp. 225-6.

[http://dx.doi.org/10.1109/VR.2015.7223377]

[93] Debarba HG, Boulic R, Salomon R, Blanke O, Herbelin B. Selfattribution of distorted reaching movements in immersive virtual reality. Comput Graph 2018; 76: 142-52.

[http://dx.doi.org/10.1016/j.cag.2018.09.001]

[94] Kishore S, Muncunill XN, Bourdin P, Or-Berkers K, Friedman D, Slater M. Multi-destination beaming: Apparently being in three places at once through robotic and virtual embodiment. Front Robot AI 2016; 3

[http://dx.doi.org/10.3389/frobt.2016.00065]

[95] Won AS, Bailenson J, Lee J, Lanier J. Homuncular Flexibility in Virtual Reality. J Comput Commun 2015; 20: 241-59.

[http://dx.doi.org/10.1111/jcc4.12107]

[96] Lugrin J-L, Wiedemann M, Bieberstein D, Latoschik ME. Influence of avatar realism on stressful situation in VR. 2015 IEEE Virtual Real. In: Conf VR 2015 - Proc. 2015; pp. 227-8.

[http://dx.doi.org/10.1109/VR.2015.7223378]

[97] Pan Y, Steed A. The impact of self-avatars on trust and collaboration in shared virtual environments. PLoS One 2017; 12(12): e0189078. [http://dx.doi.org/10.1371/journal.pone.0189078] [PMID: 29240837]

[98] Parmar D. Evaluating the effects of immersive embodied interaction on cognition in virtual reality. 2017.

[http://dx.doi.org/10.1016/j.bpobgyn.2016.03.007]

[99] Pasqualini I, Blefari ML, Tadi T, Serino A, Blanke O. The architectonic experience of body and space in augmented interiors. Front Psychol 2018; 9: 375.

[http://dx.doi.org/10.3389/fpsyg.2018.00375] [PMID: 29755378]

[100] Lugrin J-L, Polyschev I, Roth D, Latoschik ME. Avatar anthropomorphism and acrophobia. Proc ACM Symp Virtual Real Softw Technol VRST. 02-04: 315-6.

[http://dx.doi.org/10.1145/2993369.2996313]

[101] Yee N, Bailenson J. The Proteus effect: The effect of transformed selfrepresentation on behavior. Hum Commun Res 2007; 33: 271-90. [http://dx.doi.org/10.1111/j.1468-2958.2007.00299.x]

[102] Newport R, Pearce R, Preston C. Fake hands in action: embodiment and control of supernumerary limbs. Exp Brain Res 2010; 204(3): 385-95.

[http://dx.doi.org/10.1007/s00221-009-2104-y] [PMID: 20012536]

[103] Kasahara S, Konno K, Owaki R, Nishi T, Takeshita A, Ito T, et al. Malleable embodiment: Changing sense of embodiment by spatialtemporal deformation of virtual human body In: Conf Hum Factors Comput Syst - Proc. 2017; pp. 6438-48.

[http://dx.doi.org/10.1145/3025453.3025962]

[104] Phillips L, Ries B, Kaeding M, Interrante V. Avatar self-embodiment enhances distance perception accuracy in non-photorealistic immersive virtual environments. Proc. - IEEE Virtual Real 2010; pp. 115-8. [http://dx.doi.org/10.1109/VR.2010.5444802]

[105] Martini M, Perez-Marcos D, Sanchez-Vives MV. What colour is my arm? Changes in skin colour of an embodied virtual arm modulates pain threshold. Front Hum Neurosci 2013; 7: 438.

[http://dx.doi.org/10.3389/fnhum.2013.00438] [PMID: 23914172]

[106] Caspar EA, Cleeremans A, Haggard P. The relationship between human agency and embodiment. Conscious Cogn 2015; 33: 226-36. [http://dx.doi.org/10.1016/j.concog.2015.01.007] [PMID: 25655206]

[107] Tsakiris M, Haggard P. The rubber hand illusion revisited: visuotactile integration and self-attribution. J Exp Psychol Hum Percept Perform 2005; 31(1): 80-91.

[http://dx.doi.org/10.1037/0096-1523.31.1.80] [PMID: 15709864] 
[108] Botvinick M, Cohen J. Rubber hands 'feel' touch that eyes see. Nature 1998; 391(6669): 756.

[http://dx.doi.org/10.1038/35784] [PMID: 9486643]

[109] Lugrin J-L, Latt J, Latoschik ME. Avatar anthropomorphism and illusion of body ownership in VR. 2015 IEEE Virtual Real. In: Conf VR 2015 - Proc. 2015; pp. 229-30.

[http://dx.doi.org/10.1109/VR.2015.7223379]

[110] Smith HJ, Neff M. Communication behavior in Embodied virtual reality. 2018 .

[http://dx.doi.org/10.1145/3173574.3173863]

[111] Doumanis I, Economou D, Nektarios N. The REVERIE human representation addresses issues related to virtual presence, communication and interaction in collaborative virtual environments. Proc - 15th IEEE Int Conf Comput Inf Technol CIT 2015, 14th IEEE Int Conf Ubiquitous Comput Commun IUCC 2015, 13th IEEE Int
Conf Dependable, Auton Se. 1584-9

[http://dx.doi.org/10.1109/CIT/IUCC/DASC/PICOM.2015.238]

[112] Bertrand P, Guegan J, Robieux L, McCall CA, Zenasni F. Learning empathy through virtual reality: Multiple strategies for training empathy-related abilities using body ownership illusions in embodied virtual reality. Front Robot AI 2018; 5: 26.

[http://dx.doi.org/10.3389/frobt.2018.00026] [PMID: 33500913]

[113] Schuemie MJ, van der Straaten P, Krijn M, van der Mast CAPG. Research on presence in virtual reality: a survey. Cyberpsychol Behav 2001; 4(2): 183-201.

[http://dx.doi.org/10.1089/109493101300117884] [PMID: 11710246]

[114] Baños RM, Botella C, Alcañiz M, Liaño V, Guerrero B, Rey B. Immersion and emotion: their impact on the sense of presence. Cyberpsychol Behav 2004; 7(6): 734-41.

[http://dx.doi.org/10.1089/cpb.2004.7.734] [PMID: 15687809]

\section{2021 Furlan and Spagnolli.}

This is an open access article distributed under the terms of the Creative Commons Attribution 4.0 International Public License (CC-BY 4.0), a copy of which is available at: https://creativecommons.org/licenses/by/4.0/legalcode. This license permits unrestricted use, distribution, and reproduction in any medium, provided the original author and source are credited. 